\title{
KONTRIBUSI GAYA KEPEMIMPINAN TRANSFORMASIONAL PADA KOMITMEN ORGANISASI (STUDI PADA BPR DI KOTA SEMARANG)
}

\author{
Agung Sedayu \\ Ririh Dian Pratiwi \\ Desy Herma Fauza \\ Progam Studi Manajemen, Fakultas Ekonomi \& Bisnis, \\ Universitas Dian Nuswantoro Semarang \\ Email : agung.sedayu@dsn.dinus.ac.id
}

\begin{abstract}
One of the problems that employees often face is the employment pressure from their superiors. The impact of the problem includes the increase of employee turnover, the decrease of employee motivation, and the increase of employee absenteeism. Such condition decreases organizational effectivity. Therefore, the first step done by the organization is to increase employee commitment in order to improve effectiveness. To increase employees' commitment, the role of leadership is very important. One of the most popular leadership styles and suitable applied in many setting is the transformational leadership style. It significantly contributes to the improvement of organizational commitment. The leadership has four dimensions: idealized influence, inspirational motivation, intellectual stimulation and individualized consideration. The current study aims to find empirical evidence of the contribution of transformational leadership styles to organizational commitment. The employees of BPR in the city of Semarang are used as samples in the study. The data used are primary data obtained from the distribution of questionnaires to respondents. This study used descriptive analysis techniques and multiple linear regression. The results prove that simultaneously transformational leadership style significantly influence the organizational commitment. Partially inspirational motivation and individualized consideration variables have a significantly positive effect on organizational commitment. However, the idealized influence and intellectual stimulation variable have no effect on organizational commitment. The findings have theoritical and practical implication. From theoritical side, the continued research need to conduct to give clearer description of the two variables relationship. From practical side, leaders of BPR can consider the findings to improve their employee commitment.
\end{abstract}

Keywords: transformational leadership style and organizational commitment

ABSTRAK: Salah satu masalah yang sering dihadapi karyawan adalah tekanan kerja dari atasan. Dampak dari masalah tersebut antara lain turnover karyawan meningkat, motivasi karyawan menurun, kemangkiran karyawan meningkat, sehingga kinerja karyawan akan menurun. Keadaan di atas tentu saja akan memiliki pengaruh pada efektivitas organisasi. Oleh karena itu, langkah awal yang sebaiknya dilakukan oleh organisasi adalah meningkatkan komitmen karyawan agar dapat meningkatkan efektivitas organisasi. Untuk meningkatkan komitmen karyawan peran kepemimpinan organisasi merupakan salah satu hal yang sangat berpengaruh. Salah satu gaya kepemimpinan yang paling popular dan cocok di banyak seting adalah gaya kepemimpinan transformasional. Secara empiris, kepemimpinan ini mampu meningkatkan komitmen organisasi karyawan. Kepemimpinan ini memiliki empat dimensi, yaitu: idealized influence, inspirational motivation, intellectual stimulation dan individualized consideration. Penelitian ini bertujuan untuk 
menemukan bukti empiris mengenai kontribusi gaya kepemimpinan transformasional terhadap komitmen organisasi. Karyawan BPR di Kota Semarang dijadikan sampel dalam penelitian ini. Data yang digunakan adalah data primer yang diperoleh dari sebaran kuesioner kepada responden. Penelitian ini menggunakan teknik analisis deskriptif dan regresi linier berganda. Hasil penelitian membuktikan bahwa secara simultan gaya kepemimpinan transformasional berpengaruh signifikan terhadap komitmen organisasi. Sedangkan secara parsial variabel inspirational motivation dan individualized consideration berpengaruh positif signifikan terhadap komitmen organisasi, namun demikian variabel idealized influence dan intellectual stimulation tidak berpengaruh terhadap komitmen organisasi. Hasil penelitian ini memiliki kontribusi teoritik maupun praktis. Secara teoritis, hasil penelitian ini mengindikasikan masih perlunya penelitian lanjutan dilakukan untuk memberikan gambaran yang lebih jelas perihal hubungan dua variabel ini. Sementara, secara praktis, manajemen organisasi, BPR khususnya, penting untuk memperhatikan temuan ini dalam mengelola komitmen karyawannya

Kata Kunci : gaya kepemimpinan transformasional dan komitmen organisasi.

\section{PENDAHULUAN}

Persaingan dunia usaha yang semakin ketat, menyebabkan organisasi saling berlomba untuk memenangkan persaingan. Salah satu upaya yang dilakukan adalah meningkatkan efektivitas organisasi, karena dengan efektivitas organisasi tujuan organisasi akan tercapai dengan baik. Namun demikian, hal tersebut tidak mudah dilakukan karena adanya problematika yang sering dihadapi karyawan di lingkungan organisasinya.

Peningkatan efektivitas organisasi bisa dilakukan dengan meningkatkan komitmen organisasi karyawan suatu organisasi. Secara teoritik maupun empiris, komitmen organisasi yang tinggi akan memiliki berbagai dampak positif bagi organisasi, seperti: penurunan turnover dan kemangkiran, motivasi dan kinerja karyawan. Park dan Rainey (2007) menjelaskan bahwa komitmen organisasi adalah adanya ikatan antara organisasi dan karyawan. Lebih jauh, Bogler dan Somech (2004) mengatakan bahwa karyawan yang terikat pada organisasi ingin memiliki peran aktif di organisasi.

Kepemimpinan merupakan determinan penting peningkatan komitmen organisasi karyawan. Secara teoris, ada sejumlah gaya kepemimpinan yang bisa diterapkan seorang pemimpin dalam organisasinya. Perihal gaya kepemimpinan yang cocok, pemimpin mesti melihat situasi anak buah yang dipimpinnya.

Salah satu gaya kepemimpinan yang paling popular dan secara empiris terbukti cocok di berbagai seting objek penelitian adalah gaya kepemimpinan transformasional. Dari sejumlah temuan penelitian terdahulu, gaya ini memiliki kontribusi signifikan pada peningkatan komitmen organisasi. Gaya kepemimpinan ini memiliki 4 dimensi, yaitu: idealized influence, intellectual stimulation, inspirational motivation dan individualized consideration. Penelitian perihal pengaruh kepemimpinan transformasional terhadap komitmen organisasi dengan obyek penelitian guru-guru di Surabaya yang dilakukan oleh Haihatu dan Rini (2007) membuktikan bahwa kepemimpinan transformatif berpengaruh pada komitmen organisasi. Begitu pula dengan penelitian yang dilakukan oleh Ahmadi et. al. (2012) yang menunjukkan hasil yang sama, yaitu gaya kepemimpinan transformasional dan transaksional berpengaruh pada komitmen organisasi.

Sementara penelitian lainnya dengan bahasan, obyek dan hasil yang berbeda dilakukan oleh Yunus dan Ibrahim (2015), Shurbagi (2014), Feizi et. al. (2014), Wiza dan 
Hianganipal (2014), Fasola et. al. (2013), Chinebell (2013), Cemaloglu et. al. (2012), serta Simon (1994). Beragam hasil yang berbeda diantara temuan penelitian menunjukkan bahwa bangunan teori kaitannya hubungan gaya kepemimpinan transformasional terhadap komitmen organisasi masih belum kuat. Penelitian lanjutan penting dilakukan untuk memberikan gambaran yang lebih jelas perihal hubungan ini. Penelitian ini mengambil objek penelitian pada BPR di Kota Semarang.

Dari uraian di atas maka pertanyaan penelitian ini adalah: 1) apakah idealized influence berpengaruh positif terhadap komitmen organisasi?, 2) apakah intellectual stimulation berpengaruh positif terhadap komitmen organisasi?, 3) apakah inspirational motivation berpengaruh positif terhadap komitmen organisasi?, 4) apakah individualized consideration berpengaruh positif terhadap komitmen organisasi?

\section{TINJAUAN PUSTAKA}

\section{Komitmen Organisasi}

Ikatan antara organisasi dan karyawannya merupakan pengertian dari komitmen organisasi menurut Park dan Rainey (2007). Sehingga tingginya komitmen karyawan pada organisasinya akan berdampak pada beberapa aspek penting organisasi, seperti menurunnya turnover karyawan, meningkatnya motivasi karyawan, menurunnya kemangkiran karyawan dan meningkatkan kinerja karyawan.

Komitmen kontinuen, normative dan afektif adalah tiga dimensi yang dimiliki oleh komitmen organisasi. Komitmen kontinuen merupakan bentuk komitmen dimana seorang karyawan tetap bergabung di organisasi karena alasan ekonomis. Seorang karyawan telah berinvestasi di organisasi dimana ia gabung, sehingga ia ingin mendapatkan return dari organisasinya. Jika ia pindah dari organisasi maka ia akan mulai dari bawah dan kehilangan kesempatan untuk mendapatkan kembalian dari invetasinya. Sementara komitmen normatif adalah suatu bentuk komitmen dimana seorang karyawan tetap bergabung di organisasi karena ia memiliki kewajiban moral untuk tetap tinggal di organisasi.

Sedangkan komitmen afektif merupakan bentuk komitmen yang menggambarkan sikap-sikap karyawan. Dimensi komitmen ini merupakan prediktor yang baik atas turnover, kemangkiran, motivasi dan kinerja karyawan. Seorang karyawan yang memiliki komitmen afektif, ia akan memiliki rasa memiliki organisasi yang baik, memiliki ikatan emosional dengan organisasi yang tinggi dan mengidentifikasikan dirinya dengan organisasi. Ia tetap berada di organisasi karena hal-hal di atas. Indikasi di atas diperkuat oleh Dubin et. al. (1975) dalam Clinebell et. al. (2013) bahwa karyawan dengan komitmen afektif yang kuat tetap ingin bergabung di organisasi karena ia ingin melakukan hal itu. Komponen ini secara umum sering dianggap sebagai konsep awal komitmen organisasi sehubungan dengan fakta bahwa Porter di sejumlah penelitiannya memfokuskan pada sebuah pendekatan satu dimensi yang sekarang digambarkan sebagai komitmen afektif.

\section{Kepemimpinan}

Kepemimpinan merupakan salah satu tema penelitian yang menarik banyak peneliti. Penelitian dilakukan dari berbagai seting yang berbeda dengan hasil yang variatif. Penelitian kepemimpinan transformasional merupakan salah satu yang memiliki porsi besar dalam penelitian kepemimpinan. 


\section{Gaya Kepemimpinan Transformasional}

Gaya kepemimpinan proaktif adalah ciri dari gaya kepemimpinan transformasional. Pemimpin membangkitkan kesadaran pengikut untuk kepentingan bersama sehingga tujuan-tujuan yang telah ditetapkan dapat tercapai. Selain hal tersebut, pemimpin transformasional juga mendorong para pengikutnya untuk melakukan suatu pekerjaan yang melebihi harapan organisasinya (Antonakis, 2003).

Kepemimpinan transformasional terdiri dari empat dimensi yaitu: idealized influence (attribute dan behavior), inspirational motivation, intellectual stimulation dan individualized consideration. Idealized influence menggambarkan tingkat dimana pemimpin dipersepsikan sebagai seorang model peran yang memberikan inspirasi (Sarros \& Santora, 2001). Pemimpin ini menseting standar nilai moral yang tinggi, mengkomunikasikan pentingnya memiliki visi bersama dan berkorban untuk kemanfaatan kelompok. Pemimpin memiliki kualitas untuk dihormati, dikagumi dan dipercaya bawahan. Pengikut merasa bangga menjalin komunikasi dengan pemimpinnya (Jain dan Duggal, 2015).

Inspirational motivation melukiskan pemimpin memotivasi bawahannya untuk berkinerja di atas rata-rata (Jail dan Duggal, 2015). Pemimpin memperkuat pengikutnya dengan menatap masa depan dengan penuh optimis (Antonakis et. al., 2003) dan bertindak sedemikian rupa yang memberi motivasi orang-orang disekitarnya dengan memberikan makna dan tantangan ke pekerjaan pengikutnya (Bass et. al., 2003). Pemimpin memiliki kualitas untuk mengkomunikasikan visi bersama sehingga bawahan mendapatkan inspirasi untuk mencapai tujuan stratejik organisasi (Jain dan Duggal, 2015).

Stimulasi intelektual menjelaskan tingkat dimana pemimpin menstimulasi usaha pengikutnya untuk menjadi lebih inovatif dan kreatif (Bass et al., 2003) dan menerima tantangan sebagai bagian dari pekerjaannya (Sarros \& Santora, 2001). Dimensi ini merupakan perilaku yang meningkatkan kesadaran bawahan untuk mencari solusi pada masalah yang ada secara kreatif. Pemimpin selalu berpikir alternatif dalam memandang setiap masalah (Jain dan Duggal, 2015).

Sementara individualized consideration berarti pemimpin memberikan perhatian secara individual pada anak buah (Sarros dan Santora, 2001). Pemimpin memperhatikan dengan seksama tentang kebutuhan individu anak buah dan memberikan tanggungjawab tertentu untuk membantunya tumbuh dan berkembang melalui tantangan personal (Judge \& Piccolo, 2004).

\section{KERANGKA KONSEPTUAL}

\section{Pengembangan Hipotesis}

Sarros \& Santora, 2001 menjelaskan bahwa dimensi idealized influence pada gaya kepemimpinan transformasional mempersepsikan bahwa pemimpin sebagai seorang model peran yang memberikan inspirasi bagi pengikutnya. Semakin pemimpin menjadi model bagi pengikutnya maka komitmen organisasi akan semakin meningkat. Hal ini didukung oleh penelitian Njoroge dan Gachunga (2015), Feizi et. al. (2014), dan Simon (1994). Hipotesis pertama dalam penelitian ini adalah:

H1: idealized influence berpengaruh positif signifikan terhadap komitmen organisasi.

Pemimpin menstimulasi usaha pengikutnya untuk menjadi lebih inovatif dan kreatif adalah penjelasan dari Bass et. al., 2003 mengenai intellectual stimulation. Oleh karena itu, semakin pemimpin menstimulasi usaha pengikutnya maka pengikutnya akan semakin 
berkomitmen terhadap organisasi. Penjelasan ini sejalan dengan hasil temuan Njoroge dan Gachunga (2015), Feizi et. al. (2014), Kent dan Cheiladurai (2001) serta Simon (1994). Berdasarkan hasil temuan dan argumentasi tersebut maka hipotesis penelitian ketiga adalah:

$\mathrm{H} 2$ : intellectual stimulation berpengaruh positif signifikan terhadap komitmen organisasi.

Inspirational motivation yang dijelaskan oleh Jain dan Duggal (2015) adalah bawahan mendapatkan inspirasi dari pemimpin untuk mencapai tujuan stratejik organisasi dengan cara mengkomunikasikan visi. Sehingga semakin pemimpin dapat memberikan inspirasi untuk bawahannya maka komitmen organisasi akan semakin meningkat. Argumentasi tersebut di dukung oleh hasil penelitian Cemaloglu et. al. (2012) dan Walumbwa dan Lawler (2003), maka hipotesis kedua yang diajukan yaitu:

H3: inspirational motivation berpengaruh positif signifikan terhadap komitmen organisasi.

Judge \& Piccolo, 2004 memberikan penjelasan bahwa individualized consideration terjadi ketika pemimpin memperhatikan kebutuhan individu anak buah dan memberikan tanggungjawab tertentu untuk membantunya tumbuh dan berkembang melalui tantangan personal. Jika anak buah diperlakukan demikian, maka komitmen organisasi anak buah akan semakin meningkat. Hal ini di dukung oleh hasil temuan dari Njoroge dan Gachunga (2015), Yunus dan Ibrahim (2015), Feizi et. al. (2014), Cemaloglu et. al. (2012), Kent dan Cheiladurai (2001) serta Simon (1994). Hipotesis keempat dari penelitian ini adalah sebagai berikut:

$\mathrm{H} 4$ : individualized consideration berpengaruh positif signifikan terhadap komitmen organisasi.

Berdasarkan penjelasan dan argumentasi di atas dapat dibuat sebuah model penelitian sebagai berikut

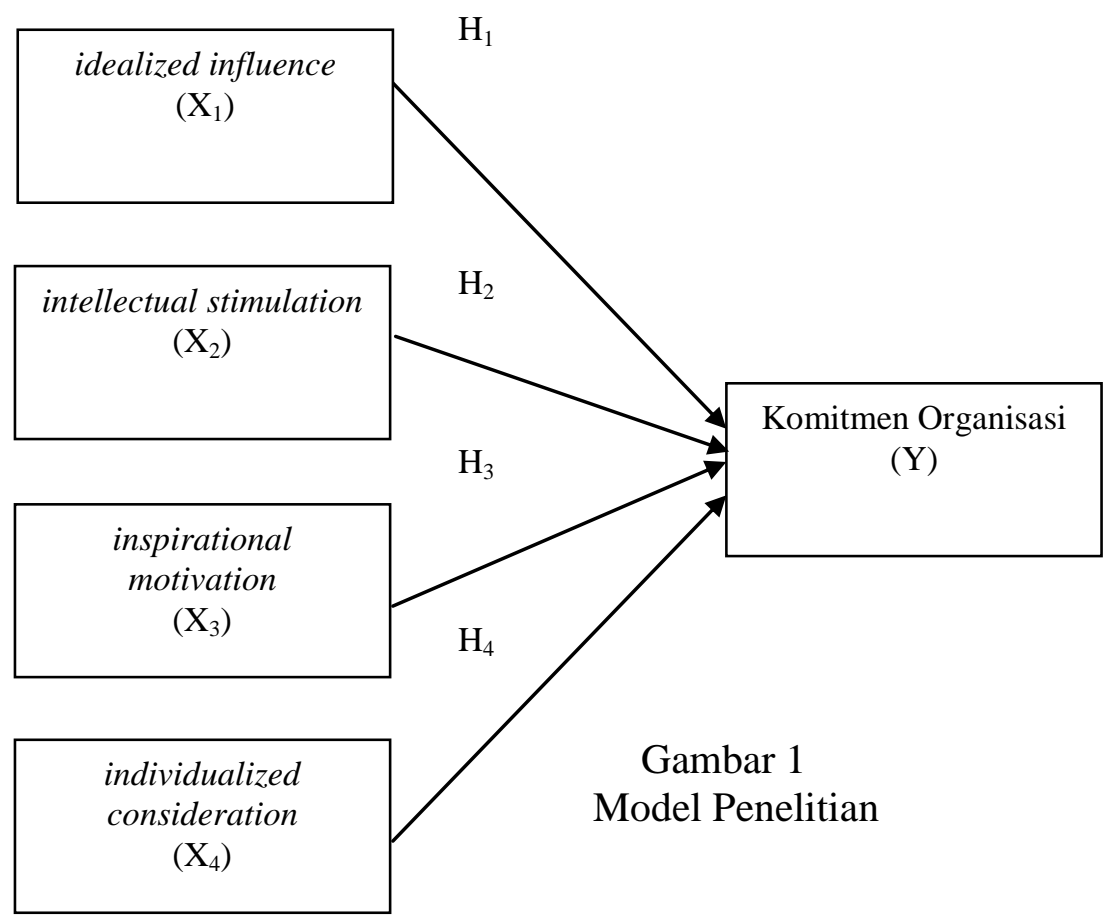




\section{METODE PENELITIAN \\ Populasi dan Sampel Penelitian}

Seluruh karyawan dari 24 BPR yang berada di Kota Semarang dijadikan populasi dalam penelitian ini. Teknik sampling yang digunakan adalah accidental sampling yaitu: teknik pengambilan sampel dimana karyawan yang ditemui dijadikan sampel penelitian. Sampel penelitian yang diperoleh berjumlah 105 responden dari berbagai karyawan BPR di Kota Semarang.

\section{Variabel Penelitian}

Variabel penelitian adalah peneliti memilih objek untuk dikaji dan selanjutnya ditarik kesimpulannya (Sugiyono, 2011). Bagian tersebut berisi deskripsi variabel-variabel yang diteliti, harus bisa didefinisikan lebih operasional. Sesudah didefinisikan variabel penelitian harus bisa diukur sesuai kaidah, dan secara akademis umum diterima. Penelitian ini menggunakan dua variabel yaitu: variabel independen dan variabel dependen.

Pengukuran variabel tersebut menggunakan skala Likert dimana setiap pernyataan diberi skor atau poin yaitu :

STS: Sangat Tidak Setuju

TS : Tidak Setuju

CS : Cukup Setuju

$S$ : Setuju

SS : Sangat Setuju

Variabel dependen adalah variabel yang dipengaruhi karena variabel independen ada (Sugiyono, 2011). Variabel dependen (Y) ialah komitmen organisasi. Pengukuran variabel dependen menggunakan indikator yaitu bangga menghabiskan karir diperusahaan, permasalahan perusahan dirasa sebagai permasalahan pribadi, keterikatan dengan perusahaan, perusahaan serasa bagian dari keluarga, keterikatan secara emosional dengan perusahaan, arti penting perusahaan, dan rasa memiliki perusahaan.

Variabel independen ialah variabel yang mempengaruhi perubahan timbulnya variabel dependen. Variabel independen $(\mathrm{X})$ terdiri dari idealized influence, inspirational motivation, intellectual stimulation dan individualized consideration.

\section{Definisi Operasional Variabel}

Definisi operasional adalah penjelasan definisi dari variabel yang telah dipilih oleh peneliti. Pendefinisian variabel penelitian harus berdasarkan pada apa yang telah dideskripsikan dalam tinjauan pustaka. Definisi operasional variabel boleh dilandaskan pada satu atau lebih rujukan, juga dibarengi argumen yang melandasi pemakaian definisi yang dimaksud.

\section{Idealized Influence (X1)}

Idealized Influence mempersepsikan bahwa pemimpin sebagai seorang model peran yang memberikan inspirasi bagi pengikutnya. Idealized Influence diukur dengan menggunakan indikator:

1) Pemimpin merasa nyaman dan bangga atas hubungannya dengan bawahan,

2) Pemimpin menjauhkan diri dari kepentingan pribadi untuk kebaikan bersama,

3) Pemimpin dihormati anak buahnya,

4) Pemimpin memiliki rasa percaya diri yang baik,

5) Pemimpin bicara tentang nilai dan keyakinan yang penting di organisasi,

6) Pemimpin memandang penting organisasi memiliki visi dan tujuan yang kuat, 
7) Pemimpin mempertimbangkan konsekuensi moral dan etik atas keputusan yang diambilnya,

8) Pemimpin menekankan pada pentingnya memiliki misi yang sama diantara anggota organisasi.

\section{Intellectual stimulation (X2)}

Intellectual stimulation adalah Pemimpin menstimulasi usaha pengikutnya untuk menjadi lebih inovatif dan kreatif. Pernyataan untuk mengukur Intellectual stimulation menggunakan indikator pernyataan sebagai berikut:

1) Pemimpin meninjau kembali asumsi penting apakah masih relevan,

2) Pemimpin memberikan sudut pandang lain ketika menyelesaikan masalah,

3) Pemimpin memberikan saran pada bawahannya untuk mendekati masalah dari berbagai sudut pandang,

4) Pemimpin menyarankan cara-cara baru digunakan untuk menyelesaikan tugas yang ada.

\section{Inspirational motivation (X3)}

Inspirational motivation adalah bawahan mendapatkan inspirasi dari pemimpin untuk mencapai tujuan stratejik organisasi dengan cara mengkomunikasikan visi. Inspirational motivation diukur menggunakan indikator sebagai berikut:

1) Pemimpin bicara tentang masa depan organisasi dengan optimisnya,

2) Pemimpin bicara tentang apa saja yang mesti diselesaikan dengan semangat,

3) Pemimpin mengartikulasikan visi masa depan organisasinya secara baik,

4) Pemimpin yakin bahwa tujuan organisasi akan tercapai.

\section{Individualized Consideration (X4)}

Individualized consideration terjadi ketika pemimpin memperhatikan kebutuhan individu anak buah dan memberikan tanggungjawab tertentu untuk membantunya tumbuh dan berkembang melalui tantangan personal. Individualized consideration diukur dengan menggunakan indikator, sebagai berikut:

1) Pemimpin menyediakan waktu untuk pembelajaran bawahannya,

2) Pemimpin memperlakukan anak buahnya secara pribadi,

3) Pemimpin memahami bahwa anak buah memiliki kebutuhan, kemampuan dan aspirasi yang berbeda-beda,

4) Pemimpin membantu anak buah untuk mengembangkan bakatnya.

\section{Komitmen Organisasi (Y)}

Komitmen organisasi adalah ikatan antara organisasi dan karyawannya. Pernyataan untuk mengukur komitmen organisasi menggunakan indikator pernyataan sebagai berikut:

1) Saya sangat bangga menghabiskan karir saya di perusahaan ini,

2) Saya benar-benar merasakan bahwa permasalahan perusahaan ini juga merupakan masalah saya sendiri,

3) Saya berpikir bahwa saya tidak mudah terikat dengan perusahaan lain seperti saya terikat dengan perusahaan ini,

4) Saya merasa menjadi bagian keluarga besar perusahaan,

5) Saya merasa terikat secara emosional dengan perusahaan ini,

6) Perusahaan ini memiliki arti yang besar buat saya,

7) Saya mempunyai rasa memiliki yang kuat terhadap perusahaan ini.

\section{Metode Analisis}

Analisis regresi linier berganda digunakan sebagai metode analisis data. Uji regresi berganda mempunyai rumus persamaan sebagai berikut: 
$\mathrm{Y}=\mathrm{a} 1+\mathrm{b} 1 \mathrm{X} 1+\mathrm{b} 2 \mathrm{X} 2+\mathrm{b} 3 \mathrm{X} 3+\mathrm{b} 4 \mathrm{X} 4+\mathrm{e}$

Keterangan:

a : konstanta

b : koefisien regresi variabel bebas

$\mathrm{X} 1$ : variabel idealized influence

$\mathrm{X} 2$ : variabel intellectual stimulation

$\mathrm{X} 3$ : variabel inspirational motivation

$\mathrm{X} 4$ : variabel individualized consideration

$\mathrm{Y}$ : variabel komitmen organisasi

e : error

\section{HASIL PENELITIAN DAN PEMBAHASAN}

\section{Hasil Regresi}

Program SPSS digunakan untuk mengolah data dalam penelitian ini sehingga diperoleh output atas data yang sudah diinput. Tahapan pengujian telah dilaksanakan tahap demi tahap. Berikut ini disajikan hasil output SPSS dalam pengujian regresi linier berganda:

Tabel 1

Regresi Berganda

Coefficients(a)

\begin{tabular}{|c|c|c|c|c|c|c|}
\hline \multirow[b]{2}{*}{ Mod } & & \multicolumn{2}{|c|}{$\begin{array}{l}\text { Unstandardized } \\
\text { Coefficients }\end{array}$} & \multirow{2}{*}{$\begin{array}{l}\text { Standardized } \\
\text { Coefficients } \\
\text { Beta }\end{array}$} & \multirow{2}{*}{$\mathrm{t}$} & \multirow{2}{*}{$\begin{array}{l}\text { Sig. } \\
\text { Std. Error }\end{array}$} \\
\hline & & $\mathrm{B}$ & Std. Error & & & \\
\hline \multirow[t]{5}{*}{1} & (Constant) & .137 & .449 & & .304 & .762 \\
\hline & Idealized_Influence & .223 & .160 & .173 & 1.394 & .166 \\
\hline & Intellectual_Stimulation & -.093 & .125 & -.086 & -.749 & .456 \\
\hline & Inspirational & .536 & .132 & .465 & 4.062 & .000 \\
\hline & $\begin{array}{l}\text { Individualized_Considerati } \\
\text { on }\end{array}$ & .242 & .117 & .193 & 2.063 & .042 \\
\hline
\end{tabular}

a Dependent Variable: Komitmen_Organisasi

Sumber : Data Primer Diolah, 2018

berikut :

Berdasarkan dari hasil regresi maka dapat dibuat persamaan linear sebagai

$Y=0,137+0,223 X_{1}-0,093 X_{2}+0,536 X_{3}+0,242 X_{4}$

\section{Koefisien Determinasi}

Tabel 2 menyajikan hasil output SPSS terkait dengan koefisien determinasi. Tabel ini menjelaskan mengenai seberapa besar kemampuan variabel $\mathrm{X}$ mempengaruhi variabel Y.

Tabel 2.

Hasil Koefisien Determinasi

Model Summary

\begin{tabular}{|l|l|l|l|l|}
\hline Model & R & R Square & $\begin{array}{l}\text { Adjusted R } \\
\text { Square }\end{array}$ & $\begin{array}{l}\text { Std. Error of } \\
\text { the Estimate }\end{array}$ \\
\hline 1 & $.654(\mathrm{a})$ & .427 & .404 & .46715 \\
\hline
\end{tabular}


Predictors: (Constant), Individualized_Consideration, Inspirational, Intellectual_Stimulation, Idealized_Influence

Sumber : Data Primer Diolah, 2018

Besarnya koefisien determinasi dapat dilihat pada Adjusted $R$ Square sebesar 0,404. Hasil ini mengandung pengertian bahwa kemampuan inspirational motivation, individualized consideration, idealized influence dan intellectual stimulation dalam menjelaskan komitmen organisasi adalah sebesar 40,4\%, sementara 59,6\% (100\%-40,4\%) komitmen organisasi dijelaskan oleh faktor-faktor lain di luar model.

$\mathbf{U j i}-\mathbf{F}$

Uji F digunakan untuk pengujian secara simultan, yaitu pengujian secara bersamasama variabel $\mathrm{X}$ terhadap variabel Y. Hasil olah data tersaji dalam tabel 3 berikut ini:

Tabel 3.

Hasil Uji - F

$\operatorname{ANOVA}(\mathbf{b})$

\begin{tabular}{|cc|c|c|c|c|c|}
\hline & & Sum of & & & & \\
Model & & Squares & Df & Mean Square & F & Sig. \\
\hline 1 & Regression & 16.270 & 4 & 4.067 & 18.638 & $.000(\mathrm{a})$ \\
& Residual & 21.823 & 100 & .218 & & \\
& Total & 38.093 & 104 & & & \\
\hline
\end{tabular}

a. Predictors: (Constant), Individualized_Consideration, Inspirational, Intellectual_Stimulation, Idealized_Influence

b. Dependent Variable: Komitmen_Organisasi

Sumber : Data Primer Diolah, 2018

Hasil uji - F sebesar 18,638 dengan sig. 0,000. Nilai sig. lebih kecil $(<)$ dari 0,05 , yang menunjukkan bahwa inspirational motivation, individualized consideration, idealized influence dan intellectual stimulation berpengaruh terhadap komitmen organisasi. Hal ini berarti inspirational motivation, individualized consideration, idealized influence dan intellectual stimulation menjadi variabel yang secara bersama-sama dipertimbangkan para pengikut/bawahan dalam berkomitmen terhadap organisasi.

\section{PEMBAHASAN}

Berdasarkan hasil uji hipotesis menunjukan bahwa ada dua variabel independen yaitu inspirational motivation dan individualized consideration terbukti berpengaruh positif signifikan terhadap komitmen organisasi. Namun demikian dua variabel independen yaitu, idealized influence dan intellectual stimulation terbukti tidak berpengaruh terhadap komitmen organisasi.

\section{Pengaruh Idealized Influence terhadap Komitmen Organisasi}

Hasil penelitian ini membuktikan bahwa dengan tingkat signifikansi 5\% idealized influence tidak berpengaruh terhadap komitmen organisasi. Hal ini terbukti dari nilai $\mathrm{t}$ hitung sebesar 0.166 (lihat tabel 1), angka tersebut menunjukkan lebih besar dari 0.05. Berarti hipotesis pertama dalam penelitian ini tidak bisa diterima. Artinya bahwa idealized influence tidak mempengaruhi komitmen organisasi. 
Argumentasi yang dapat mendukung hasil penelitian tersebut adalah, idealized influence belum dapat berjalan dengan efektif dan efisien. Pemimpin bisa jadi dipersepsikan belum sepenuhnya memiliki rasa percaya diri yang baik dalam memimpin. Pemimpin bisa jadi juga kurang dalam hal diskusi masalah nilai dan keyakinan yang penting di organisasi. Selanjutnya, anak buah bisa jadi memandang pemimpinnya belum memiliki visi dan misi yang kuat perihal kemana arah organisasi dijalankan. Selain itu, anak buah bisa jadi mempersepsikan bahwa keputusan yang diambil pemimpinnya terkadang belum mempertimbangkan konsekuensi moral dan etisnya. Dampak dari persepsi anak buah ini menyebabkan komitmen pengikutnya tidak meningkat. Temuan penelitian ini sesuai dengan hasil penelitian dari Cemaloglu et al. (2012), Kim dan Kim (2014), tetapi hal tersebut tidak sesuai dengan temuan penelitian Njoroge dan Gachunga (2015), Feizi et. al. (2014), dan Simon (1994).

\section{Pengaruh Intellectual Stimulation terhadap Komitmen Organisasi}

Berdasarkan informasi yang tersaji dalam tabel 1, terbukti bahwa dengan tingkat signifikansi 5\% intellectual stimulation tidak berpengaruh terhadap komitmen organisasi. Hal ini terbukti dari nilai t hitung sebesar 0.456, angka tersebut menunjukkan lebih besar dari 0.05. Berarti hipotesis kedua dalam penelitian ini tidak bisa diterima. Artinya bahwa intellectual stimulation tidak mempengaruhi komitmen organisasi.

Alasan yang dapat mendukung hasil penelitian tersebut adalah bahwa intellectual stimulation merupakan salah satu dimensi dari kepemimpinan transformasional yang fokus pada penyelesaian kreatif terhadap masalah yang ditemui dalam organisasi. Anak buah bisa jadi mempersepsikan pemimpinnya belum memberikan sudut pandang lain ketika menyelesaikan masalah. Artinya penyelesaian masalah yang dilakukan karyawan belum dilihat dari berbagai sudut pandang. Sementara ciri dimensi ini adalah bahwa pemimpin memberikan saran pada bawahannya untuk mendekati masalah dari berbagai sudut pandang. Disamping itu, dimensi ini juga menekankan pada pemimpin untuk menyarankan cara-cara baru untuk menyelesaikan tugas yang ada. Anak buah memandang bahwa pemimpinnya belum berperan seperti yang diuraikan di atas. Keadaan ini tentu tidak meningkatkan komitmen organisasi anak buah.

Temuan penelitian ini sesuai dengan hasil penelitian dari Yunus dan Ibrahim (2015), Kim dan Kim (2014) dan Cemaloglu et al. (2012), tetapi hal tersebut tidak sesuai dengan temuan penelitan Njoroge dan Gachunga (2015), Feizi et. al. (2014), Kent dan Cheiladurai (2001) serta Simon (1994).

\section{Pengaruh Inspirational Motivation terhadap Komitmen Organisasi}

Tabel 1 membuktikan bahwa dengan tingkat signifikansi 5\% inspirational motivation berpengaruh positif signifikan terhadap komitmen organisasi. Hal ini terbukti dari nilai t hitung sebesar 0.000 dengan nilai beta menunjukkan arah positif. Berarti hipotesis ketiga dalam penelitian ini diterima. Artinya bahwa semakin tinggi inspirational motivation maka komitmen organisasi juga akan semakin tinggi.

Substansi dari dimensi ini adalah bahwa bagaimana pemimpin bicara tentang masa depan organisasi dengan optimisnya. Anak buah mempersepsikan pemimpin bicara tentang apa saja yang mesti diselesaikan dengan semangat. Disamping itu, anak buah juga mempersepsikan bahwa pemimpin mengartikulasikan visi masa depan organisasinya secara baik. Anak buah juga mempersepsikan bahwa pemimpin yakin bahwa tujuan organisasi akan tercapai. Keadaan ini memberi kontribusi pada peningkatan komitmen anak buah pada organisasi. 
Hasil penelitian ini sesuai dengan temuan penelitan Cemaloglu et. al. (2012) dan Walumbwa dan Lawler (2003), yang menyatakan bahwa inspirational motivation mempengaruhi komitmen organisasi.

\section{Pengaruh Individualized Consideration terhadap Komitmen Organisasi}

Terbukti bahwa dengan tingkat signifikansi 5\% individualized consideration berpengaruh positif signifikan terhadap komitmen organisasi. Hal ini terbukti dari nilai $t$ hitung sebesar 0.042 dengan nilai beta menunjukkan arah positif. Berarti hipotesis terakhir dalam penelitian ini diterima. Artinya bahwa semakin tinggi individualized consideration maka komitmen organisasi juga akan semakin tinggi.

Substansi dimensi ini adalah bahwa pemimpin menyediakan waktu untuk yang cukup untuk pembelajaran bawahannya. Anak buah mempersepsikan pemimpinnya memberikan alokasi waktu untuk meningkatkan kualitas anak buahnya. Selain itu, pemimpin juga dipersepsikan sebagai sosok yang bisa memperlakukan anak buahnya secara pribadi. Artinya anak buah memandang bahwa pemimpin yang memberikan perhatian secara pribadi pada anak buah bisa meningkatkan komtimennya. Anak buah juga mempersepsikan bahwa pemimpinnya mengetahui dan memahami bahwa anak buah memiliki kebutuhan, kemampuan dan aspirasi yang berbeda-beda. Pemahaman ini penting agar keputusan organisasi yang dibuat pemimpin bisa sesuai dengan kebutuhan dan juga aspirasi anak buah. Anak buah juga mempersepsikan bahwa pemimpin membantu anak buah dalam mengembangkan bakatnya. Keadaan ini bisa meningkatkan komitmen organisasi karyawan.

Hasil penelitian ini sesuai dengan temuan penelitan Njoroge dan Gachunga (2015), Yunus dan Ibrahim (2015), Feizi et. al. (2014), Cemaloglu et. al. (2012), Kent dan Cheiladurai (2001) serta Simon (1994), yang menyatakan bahwa individualized consideration mempengaruhi komitmen organisasi.

\section{KESIMPULAN}

Hasil penelitian menunjukkan bahwa dua dimensi kepemimpinan transformasional yaitu inspirational motivation dan individualized consideration terbukti berpengaruh positif signifikan terhadap komitmen organisasi. Sedangkan variabel idealized influence dan intellectual stimulation terbukti tidak berpengaruh terhadap komitmen organisasi. Hasil penelitian ini memiliki implikasi manajerial, yaitu pemimpin dalam mengelola anak buahnya mesti meningkatkan motivasi karyawan. Pemimpin penting juga memberikan inspirasi pada anak buah. Selain itu pemimpin juga penting untuk meningkatkan perhatian secara individu pada karyawan. Perhatian secara individu pada karyawan dapat meningkatkan ikatan emosional karyawan pada organisasi dan pemimpinnya. Selain itu, perhatian secara pribadi pada karyawan juga bisa meningkatkan motivasi dan keterlibatan karyawan pada aktivitas organisasi.

\section{DAFTAR PUSTAKA}

Ahmadi et al. (2012). Effect of the Leadership Styles on the Organizational Commitment Given the Staff Personality Traits (The Case Study; Iran's State Retirement Organization. Interdiciplinary Journal of Contemporary Research Business. 
Antonakis, J. Avolio, B.J., \& Sivasubramaniam, N. (2003). Context and leadership: an examination of the nine-factor full-range leadership theory using the Multifactor Leadership Questionnaire. The Leadership Quarterly. 14 (3), 261-295

Bass, M.B. et al. (2003). Predicting unit performance by assessing transformational and transactional leadership. Journal of applied psychology Vol. 88 Number 2. 207-218

Bogler dan Somech (2004). Influence of teacher empowerment on teachers' organizational commitment, professional commitment and organizational citizenship behavior in schools. Teaching and Teacher Education

Cemaloglu et al. (2012). Examining the Relationship between School Principals's Transformational and Transactional Leadership Styles and Teachers' Organizational Commitment. The Online Journal of New Horizons in Education. April. Vol. 2 Issue 1

Clinebell et al (2013). Impact of Leadership Styles on Employee Organizational Commitment. Journal of Service Science. Vol 6 No. 1

Fasola et al. (2013) Exploring the Relationship between Transformational, Transactional Leadership Style and Organizational Commitment among Nigerians Banks Employees. International Journal of Academic Research in Economics and Management Sciences. November. Vol. 2. No.6. ISSN: 2226-3624

Feizi et al. (2014). Investigating the Relationship between Transformational Leadership and Organizational Commitment of High School Teachers in Germi. International Journal of Organizational Leadership. 17-30

Jain dan Duggal (2015). The role of Transformational Leadership in Organizational Commitment. International Journal of Business Quantitative Economics and Applied Research. ISSN: 2349-5677. Volume 2, Issue 5.

Judge, T.A., \& Piccolo., R.F. (2004) Transformational and Transactional leadership: A Meta-Analytic test of their relative validity. Journal of Applied Psychology, 89(5), 755-768

Haihatu dan Rini (2007). Kepemimpinan Tranformasional dan Pengaruhnya terhadap Kepuasan atas: Kualitas Kehidupan Kerja, Komitmen Organisasi dan Perilaku Ekstra Peran: Studi pada Guru-Guru SMu di Kota Surabaya. Jurnal Manajemen dan Kewirausahaan. Vol 98. No. 1

Kent dan Cheiladurai (2001). Perceived transformational leadership, organizational commitment and citizenship behavior. A case study in intercollegiate athletics. J. Sport Manage.

O'Driscoll dan Beehr (1994). Supervisor behaviors, role stressors and uncertainty as predictors od personal outcomes for subordinate. Journal of Organizational Behavior, 15, 141-155

Park dan Rainey (2007). Antecendents, mediators and consequences of affective, normative and continuance commitment. Empirical tests of commitment effects in federal agencies. Review of Public Personnel Administration, 27 (3), 197-226

Sarros, J.C. \& Santora, J.C., (2001). The transformational-transactional leadership model in practice.Leadership \& Organizational Development Journal, 22(8), 383-393

Shurbagi (2014). The Relationship between Tranformational Leadership and Organizational Commitment in National Oil Corporation of Libya. $3^{\text {rd }}$ International Coneference on Humanities, Economics and Geography. March 19-20. Abu Dhabi

Simon (1994). Trust in Leadership: Its Dimensions and Mediating Role. Unpublished Dissertation. Manhattan. Kansas State University 
Walumbwa dan Lawler (2003). Building effective organization: transformational leadership, collectivist orientation, work-related attitudes and withdrawal behaviors in three emerging economies. Int. J. Hum. Res. Manage

Wiza dan Hianganipal (2014). The Impact of Leadership Styles on Employee Organizational Commitment in Higher Learning Institutions. Mediterranean Journal of Social Sciences. MCSER Publishing. March. Vol. 5 No. 4

Yunus dan Ibrahim (2015). Employees' Organizational Commitment: The effect of Leaders' Transformational Leadership and Leader-Member Exchange as Moderator. International Journal of Arts and Commerce. Vol. 4 No. 2 February. 